\title{
INTERVENCIONES POSESTRUCTURALES
}

\author{
J. K. GibSOn-Graham \\ Department of Human Geography, \\ The Australian National University \\ katherine.gibson@anu.edu.au \\ Department of Geosciences, University of Massachusetts \\ graham@geo.umass.edu
}

\begin{abstract}
Resumen
[ L POSESTRUCTURALISMO ES UNA APROXIMACIÓN TEÓRICA AL CONOCIMIENTO Y LA [ sociedad que acoge la incertidumbre de los significados, el poder constitutivo del discurso y la efectividad política de la teoría y la investigación. Las autoras exploran tres conceptos/estrategias posestructuralistas -la deconstrucción, la genealogía y la performatividad-resaltando su uso en la geografía económica. El artículo concluye con una exploración acerca de la manera como el posestructuralismo transforma y politiza la práctica de la investigación social. Al respecto se consideran tres proyectos de investigación posestructuralistas que se involucran en producir o desestabilizar formaciones discursivas, y de esta forma participan en la construcción de poder, subjetividad y posibilidad social.

PALABRAS ClaVES: reconstrucción, genealogía, performatividad, investigación social, investigación-acción.
\end{abstract}

\section{Abstract}

D OSTSTRUCTURALISM IS A THEORETICAL APPROACH TO KNOWLEDGE AND SOCIETY THAT embraces the ultimate undecidability of meaning, the constitutive power of discourse, and the political effectivity of theory and research. In this paper the authors explore three poststructuralist concepts/strategies -deconstruction, genealogy, and performativity- highlighting their uses in economic geography. The paper concludes with an exploration of how poststructuralism transforms and politicizes the practice of social research. In relation to this, they examine three poststructuralist research projects that actively engage in producing or destabilizing discursive formations, thereby participating in the constitution of power, subjectivity and social possibility.

KEY WORDS: deconstruction, genealogy, performativity, social research, action research.

Revista Colombiana de Antropología

Volumen 38, enero-diciembre 2002, pp. 26I-286 


\section{INTRODUCCIÓN*}

L POSESTRUCTURALISMO ES UNA APROXIMACIÓN TEÓRICA AL CONOCI- miento y la sociedad que acoge la incertidumbre de los signiL ficados, el poder constitutivo del discurso y la efectividad política de la teoría y la investigación. Comenzó en la década de Ig60 como un movimiento dentro de la filosofía francesa, y después migró hacia el mundo angloparlante donde tuvo también un impacto transformativo en la filosofía, al igual que en los estudios literarios y culturales. En épocas más recientes, ha ganado espacio dentro de la geografía humana y otras ciencias sociales. Este artículo ofrece una breve reseña de las principales contribuciones y preocupaciones de esta tradición teórica relativamente nueva y traza su desarrollo dentro de la geografía económica, dando cuenta de sus poderes y potencialidades.

Algunas veces, el posestructuralismo es equiparado al posmodernismo, un término que tiende a definirse de manera amplia. Por ejemplo, en la geografía el posmodernismo hace referencia de forma diversa a una época histórica (Harvey, I989) caracterizada por unas prácticas socioeconómicas particulares y unas condiciones ideológicas; a un estilo estético en las películas, la arquitectura y otras formas culturales; o a una aproximación teórica al conocimiento y la sociedad (Gibson y Watson, I995: I). Esta última es lo que estamos llamando posestructuralismo - una aproximación al conocimiento y al mundo, sustentada filosóficamente y distintiva teóricamente (Amariglio, 1999)-. Lo que resulta posmoderno del posestructuralismo es su rechazo de ciertas concepciones modernistas, claramente identificables, sobre el

* Traducción de Santiago Giraldo, Instituto Colombiano de Antropología e Historia (ICANH). Este artículo fue publicado originalmente en E. Sheppard y T. Barnes (editores). A Companion to Economic Geography. Blackwell. Oxford. Su reproducción en esta revista es posible gracias a las autoras y al ICANH, que adquirió los derechos de publicación de Blackwell. conocimiento, el conocedor y lo conocido. Mientras que se entiende que el conocimiento dentro de un marco modernista es singular, acumulativo y neutral, desde una perspectiva posestructural es múltiple, contradictorio y poderoso. Lo que deseamos explorar en este ensayo son sus implicaciones para la geografía económica. 


\begin{tabular}{r|r} 
Revista Colombiana & \\
de Antropología & 263 \\
\hline Volumen 38, enero-diciembre 2002 &
\end{tabular}

\section{Antecedentes y ORÍGENES POSESTRUCTURALISTAS}

L L POSESTRUCTURALISMO EMERGE DENTRO Y EN CONTRA DE LA TRADICIÓN - modernista del estructuralismo. Quizá su antecedente más - cercano sea el estructuralismo lingüístico de Ferdinand de Saussure, que rechazó la visión de la lingüística tradicional en la que las palabras se consideran símbolos que representan objetos en el mundo. Saussure (I966), en cambio, sostuvo que las palabras podían ser vistas como signos constituidos por la relación entre dos partes, el significante -la imagen visual o acústica- y el significado -el concepto evocado por esta imagen-. En cualquier lenguaje el significado no emerge de la relación entre las palabras y sus referentes extralingüísticos, lo cual es enteramente arbitrario, sino de las relaciones de diferencia construidas socialmente entre los signos (Yapa, I999a).

Consideremos la palabra fábrica. Desde un punto de vista pre-saussuriano, esta palabra es un símbolo que representa un edificio donde se lleva a cabo la producción -su referente en el mundo real-. En oposición, desde el punto de vista estructuralista de Saussure, la palabra fábrica es un signo que incluye la palabra escrita o hablada FÁBRICA (el significante) y la IDEA (el significado) de un edificio que se diferencia de otras cosas debido a las prácticas culturalmente codificadas que ocurren en y alrededor de él. La palabra fábrica adquiere significado por medio de lo distintivo de su signo en relación con todos los otros signos del lenguaje, por ejemplo, al diferenciarse de signos como oficina o casa o campo o parque de juegos. Lo revolucionario de esta declaración es afirmar que el significado se crea dentro de una estructura social compleja de relación y diferencia y no por medio de palabras que operan como sustitutos para los objetos, representándolos en su ausencia (Hewitson, I999).

Aunque el estructuralismo se considera como algo que desestabiliza la presuposición modernista en la que el lenguaje es un espejo de la realidad, también es un proyecto esencialmente modernista. Para los pensadores estructuralistas, subyacentes a los flujos y contingencias del mundo social se encontraban las formaciones unificadas que configuraban la vida social. Las teorías lingüísticas de Saussure, culturales de Claude Lévi-Strauss, económicas de Karl Marx y psicoanalíticas de Sigmund Freud, 
cada una a su manera, aducían el origen y la organización de fenómenos sociales complejos a estructuras más profundas. Desvelar o descubrir esas estructuras era la tarea de la ciencia estructural (Amariglio, 1999).

Aquellos filósofos que llegarían a ser conocidos como posestructuralistas confrontaron el proyecto estructuralista, tomando una actitud escéptica hacia la determinación por estructuras subyacentes y los intentos de encontrar la verdad última del lenguaje,la cultura, la sociedad y la psiquis. Pero quizá su movimiento más notorio fue cuestionar la relación inmóvil entre significante y significado, que caracterizaba a la lingüística saussuriana. Desde una perspectiva posestructuralista, el lenguaje no existe como un sistema de diferencias dentro de un conjunto único de signos. En cambio, las relaciones significante-significado se crean y revisan continuamente, ya que las palabras se recontextualizan en una producción eterna de textos. La creación de significado es un proceso inacabado, un sitio de constante forcejeo -político- donde se generan significados alternos y cuya firmeza es apenas temporal.

Así, el significado de la palabra mujer en el contexto de marido, hogar y familia, es muy distinto a su significado en el contexto lesbiana, trabajo y política. Las luchas políticas feministas pueden considerarse un multiplicador de los contextos y significaciones de mujer, que en el proceso desestabilizan aquellos significados inmóviles asociados a un orden patriarcal (Daly, I99I).

Hasta este momento, en la discusión nos hemos encontrado con el antifundamentalismo y el antiesencialismo que caracterizan a la teoría posestructuralista. Una epistemología antifundamentalista se rehúsa a considerar el conocimiento como algo "basado en la realidad" o que está encargado de ser reflejo ${ }^{1}$ de o reflejar el mundo (Rorty, I979). En vez de ser un reflejo que depende de una realidad independiente, I. Mirroring, en el original (N. del t.). el conocimiento posestructural es un proceso social que interactúa plenamente con otros procesos sociales y naturales que constituyen la vida social. La epistemología antifundamentalista está relacionada directamente con una ontología antiesencialista. Si la palabra mujer no corresponde directamente a un ser humano femenino genérico, su significado no puede entenderse como fijado por una equivalencia esencial que unifica a todas las mujeres. Al contrario, la palabra mujer se resignifica cada vez que 


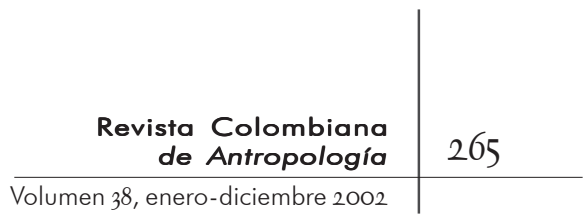

se recontextualiza. No hay un concepto esencial, fundamental o invariable de mujer que ancle la palabra, sino una infinidad de contextualizaciones que proveen lecturas múltiples y contradictorias de lo que es o puede ser mujer.

A pesar de su antagonismo hacia lo fundamental, los pensadores estructuralistas no ven al significado y al conocimiento como algo desligado de otros aspectos de la vida social. Se entiende pues que el significado se produce bajo condiciones sociales e intelectuales específicas y que el conocimiento no es un reflejo verdadero sino una fuerza productiva y constitutiva. Aunque los conocimientos no pueden ser diferenciados de acuerdo con un mayor o menor grado de precisión -su éxito o fracaso para reflejar el mundo-, sí pueden distinguirse por sus efectos -los diferentes sujetos a los que otorgan poder, las instituciones y prácticas que permiten, al igual que aquellos que excluyen o suprimen-. De esta forma, el tipo de conocimiento producido es un problema de consecuencia y no de indiferencia.

\section{EstrategiAs POSESTRUCTURALISTAS}

\footnotetext{
L POSESTRUCTURALISMO OFRECE UNA VARIEDAD DE ESTRATEGIAS QUE cuestionan las ideas recibidas y las prácticas dominantes, haciendo visible su poder y creando espacios para que emerjan formas alternas de la práctica y el poder. Las que exploramos aquí son la deconstrucción, la genealogía y el análisis discursivo.
}

\section{Deconstrucción}

I A DECONSTRUCCIÓN ES UN TIPO DE LECTURA QUE SE ORIGINA EN LA $\longrightarrow$ obra del filósofo francés Jacques Derrida (I967). Trabajando en contra de lo que él denomina la "metafísica de la presencia”, o el "logocentrismo", Derrida cuestiona ciertos axiomas fundamentales del pensamiento occidental. Algunos de los presupuestos cuestionados son:

* La ley de la identidad y la presencia del ser (si un edificio es fábrica es una fábrica). 


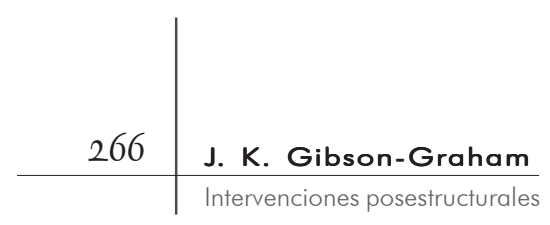

* La ley de la no-contradicción que establece la identidad en relación con su "otro" (si una cosa es una fábrica, no puede ser también una no-fábrica); y

* La ley de exclusión del medio (fábrica y no-fábrica contienen todas las posibilidades de una situación dada) (Jay, I99r: 92-93; Gross, I986: 26-28; Hewitson, 1999: 4).

En conjunto, estas leyes nos dan objetos/identidades estables, circunscritos y que se constituyen mediante una negación -de todo lo que no es fábrica-.

Lo que Derrida identifica como logocentrismo es el patrón occidental de producir significado mediante una estructura binaria positiva y negativa (A/no A, fábrica/no fábrica). Dentro del marco del logocentrismo, el primer término de una estructura binaria está dotado de positividad ${ }^{2}$ a expensas del otro -presencia y valor están adjuntos a fábrica, mientras que el término no-fábrica está ausente y devaluado. La estructura binaria establece una relación de oposición y exclusión y no una relación de similitud y mezcla entre los dos términos -así, si la fábrica es un sitio de producción, entonces la no-fábrica, algo como un hogar, no lo es; o si la producción existe dentro del hogar, esta es inferior a la que se lleva a cabo en la fábrica-. Esta estructura de oposición está asociada con una metafísica de la valoración que puede ser muy sutil pero imposible de evadir -la tendencia dominante a tomar en serio la presencia, la positividad y el ser y a descontar la ausencia, la negación y

2. Positividad no es una palabra aceptada por la Real Academia Española de la Lengua, de igual forma que positivity no es de uso común en inglés, por lo que decidí conservar la acepción original dada a la palabra por Gibson-Graham (N. del t.).

3. En el original en inglés es el becoming, relacionado con la pregunta del Ser planteada por Heidegger y discutida por Derrida en De la Grammatologie. Les Editions du Minuit. París. I967 (N. del t.) . el no-ser/llegar al ser- ${ }^{3}$. Mediante este ejemplo es fácil ver cómo el logocentrismo puede dar pie a que surja un concepto tal como economía; circunscrito, estable e inherentemente más importante que lo no-económico.

El estructuralismo feminista, entre otros, ha observado cómo los intentos para (re)valorar el término ausente o subordinado dentro de una estructura binaria son minados fácilmente. Esto revela la presencia de lo que Saussure identificó como un significante maestro que opera para estabilizar las relaciones de diferencia. El feminismo posestructuralista ha cambiado el término logocentrismo 


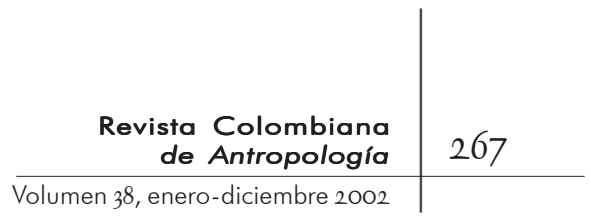

por falogocentrismo, recalcando la forma en que la figura masculina -el falo- fija el significado, dando presencia y positividad a un lado de la estructura binaria y produciendo una cadena alineada de términos dominantes dentro del pensamiento europeo de la ilustración, como en los ejemplos siguientes:

$\begin{array}{lll}\text { Hombre } & / & \text { mujer } \\ \text { Mente } & / & \text { cuerpo } \\ \text { Razón } & / & \text { emoción } \\ \text { Objetividad } & / & \text { subjetividad } \\ \text { Yo } & / & \text { otro } \\ \text { Economía } & / & \text { sociedad } \\ \text { Producción } & / & \text { reproducción } \\ \text { Fábrica } & / & \text { hogar }\end{array}$

Podemos detectar el rol del falo como un significante maestro por medio de la regularidad con la que se asocia el primer término con masculinidad, predominancia e importancia. Volviendo a nuestro ejemplo de la fábrica, la identidad y positividad de la fábrica se obtiene dentro de una estructura sociolingüística que asocia lo que ocurre en la fábrica con razón, objetividad, mente, hombre y economía. Estos términos dominantes se refuerzan el uno al otro, diferenciando la producción en la fábrica de los tipos de producción en los hogares, los patios traseros, las calles y los campos, dándole un mayor grado de realidad, independencia y consecuencia.

Como parte de un proyecto político para crear espacios de heterogeneidad radical, la estrategia deconstructiva de Derrida se interesa en pensar las diferencias por fuera de las estructuras binarias y jerárquicas. Una deconstrucción derrideana del signo FÁBRICA puede comenzar por revalorar el término subordinado en la estructura binaria fábrica/no-fábrica. Por ejemplo, las teóricas feministas de la economía han tratado de revertir el flujo de la valoración cultural, anotando cuántas horas ocupan las labores domésticas no remuneradas y cómo esta contribución al producto interno bruto, si se midiera, sobrepasaría todo el trabajo efectuado dentro de la producción fabril (Waring, I988). Llevando el análisis un poco más lejos, en la geografía económica es tradicional ver al hogar como el sitio de la reproducción 


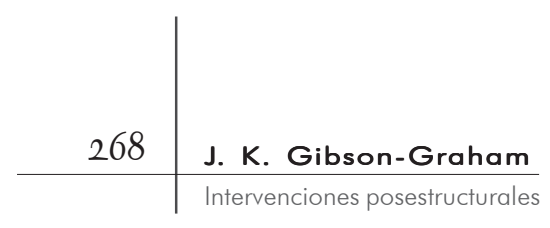

social -una serie de prácticas dependientes, tales como las labores domésticas y el cuidado de los hijos, poco determinantes y que por lo general son subvaloradas-. Al revertir la estructura binaria producción/reproducción, la reproducción podría representarse como la actividad que compromete a todas las personas durante todo el tiempo; como el proceso íntegro de crear las condiciones para que la sociedad continúe existiendo. Así, reproducción es un concepto que abarca más que producción. Es el caso general, el todo del cual la producción es una parte, mientras que la producción es el caso especial.

Uno de los problemas del proceso de revertir es que mantiene intacta la estructura binaria, cambiando simplemente la jerarquía de valoración. Otra estrategia deconstructiva aún más potente es la de desdibujar los límites entre los términos, socavando la solidez y fijeza de la identidad/presencia, mostrando cómo el otro excluido se encuentra incrustado de tal forma dentro de la identidad primaria que su diferencia resulta insostenible. Así, el hogar podemos representarlo también como un sitio de producción -de varios bienes y servicios domésticos- y la fábrica como un lugar de reproducción. Aquellas actividades consideradas como no económicas que se dice ocurren en el espacio doméstico -el despliegue de emociones, la representación de identidades sexuales y de género, la socialización, el entrenamiento, el cariño- no se efectúan solo en el espacio público de la fábrica sino que, incluso, puede considerarse que desmejoran la integridad de esta como un espacio eficiente de la producción, el cálculo racional y la maximización de las utilidades. La presencia interna del otro excluido vuelve la identidad algo poco familiar, vaciándola de significado (Doel, I994). Súbitamente, lo que entendíamos por fábrica comienza a desmoronarse.

La deconstrucción ilumina los momentos de contradicción e indecisión de lo que parece ser una estructura o texto nítidamente concebidos (Ruccio, I999). Enseña la postergación indefinida del significado dentro de un sistema de diferenciación y coloca en primer plano la incapacidad que tiene el signo de personificar totalmente un significado esencial. El significado es creado y re-creado dentro de textos y contextos específicos. Ya que no existe un término maestro para fijar los conceptos a significantes específicos, el significado siempre está en proceso e incompleto. 


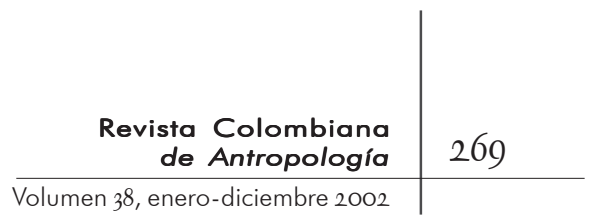

\section{Genealogía y análisis discursivo}

Mientras que Derrida ENFatiza lo Móvil ${ }^{4}$ y disputable DEl Signido se ve constreñido por la metafísica de la presencia-, el proyecto de Michel Foucault se dirige a

examinar la manera como ciertos Co- 4 . Unfixity en el original ( $N$. del t.). nocimientos y significados son normalizados y aceptados como Verdad. El trabajo de Foucault enfatiza sobre las formas en las que la construcción de significado es una representación del poder que no sólo se encuentra trazada en el lenguaje sino también grabada sobre el cuerpo y re-constituida continuamente en la vida social. Al usar el término discurso, Foucault se refiere a una práctica gobernada por reglas, que incluye significados enmarcados dentro de un sistema de conocimiento $\mathrm{y}$ en instituciones y prácticas sociales que producen y mantienen estos significados (I99I). Volviendo a nuestro ejemplo de la fábrica, un cobertizo con techo en forma de serrucho donde la gente toma unos materiales y, usando varias clases de máquinas, los transforma en otros materiales es conocido como fábrica, tanto por la diferenciación de FÁBRICA dentro de un sistema de signos lingüísticos como por su posición en un sistema de signos aún más amplio, conformado por las convenciones sociales, los movimientos corporales rutinarios, las reglas de comportamiento y los actores institucionales, entre otros. Este conjunto de metal, vidrio, cuerpos, energía y materiales producidos cobra significado y se le da un valor positivo sólo dentro del discurso -en este caso, quizás, un discurso de industrialización-.

Foucault desafía la universalidad y verdad del significado al desarrollar un método distintivo para el análisis del discurso que involucra: I) un análisis crítico de las violencias generadas por cualquier teoría o sistema de significados (lo que excluye, prohíbe o niega); y 2) un análisis genealógico de los procesos, continuidades y discontinuidades mediante las que llega a formarse un discurso (198I). Su trabajo dirige nuestra atención hacia las formas en que los conocimientos ejercen y producen poder -por medio de aparatos de regulación; por ejemplo, instituciones como escuelas, prisiones, casa de trabajo y fábricas en donde prevalecen las técnicas de disciplina y vigilancia corporal-, y mediante el desarrollo y aplicación de tecnologías para administrar el ser -por ejemplo, presupuestos, dietas, mapas, columnas de 
ayuda sexual, propagandas de productos de higiene personal-que ayudan a organizar la vida diaria. Un análisis crítico del discurso de la industrialización podría ilustrar la manera como los cuerpos y la producción material que se lleva a cabo en los hogares son devaluados dentro de los sistemas de saber disciplinarios de la economía y la geografía económica. Tal genealogía podría comenzar, por ejemplo, con una noción fisiocrática de la economía, en la que un excedente agrícola hace posibles las actividades no agrícolas -estableciendo de esta forma la dependencia y estatus secundario de la industria-. Podría virar, entonces, hacia la centralidad y estatus originario de la industria en el discurso de la industrialización, con su visión de la economía y el crecimiento económico -incluyendo la demanda de productos y servicios agrícolas- siendo impulsados por los incrementos en la producción manufacturera; y, finalmente, a la literatura sobre la economía posindustrial, en la que instituciones y transacciones financieras de alto nivel establecen una vez más la subordinación de la industria, esta vez a la especulación financiera y los azares del sector financiero internacional. Lo que emerge de este proyecto que traza los saberes cambiantes de industria es una concepción relativamente estable de la economía como una totalidad integrada, centrada sobre un espacio determinante que constriñe, impulsa o

5. La palabra queer no admite una traducción literal al español y por eso se conserva en inglés. Literalmente significa raro o extraño, pero su uso en este texto hace referencia a todos aquellos comportamientos que se salen de lo que la sociedad define como normal y que son clasificados como desviados, raros, extraños o anormales. Otros prefieren resaltar que es todo comportamiento que se sale de, atenta contra o subvierte lo heteronormativo; aquellas reglas y normas sociales acerca de las conductas aceptables que corresponden a hombres y mujeres, lo femenino y lo masculino, y que desestabilizan la asignación de sexo, género o sexualidad (N. del t.). dicta hacia otros sitios/actividades. Por medio del proceso de genealogía, esta noción se ve desnaturalizada, haciéndola visible como una construcción discursiva.

La influencia de Foucault sobre el posestructuralismo ha concentrado la atención sobre cómo las diferentes formas de poder están entrecruzadas con la producción de conocimiento para crear ciertas concepciones valorizadas del asunto en cualquier periodo histórico. Aunque gran parte del trabajo de Foucault parece enfatizar sobre la construcción y consolidación de discursos dominantes que someten al individuo a fuerzas poderosas fuera de su control, su intervención abre también un espacio para examinar la proliferación y multiplicidad de discursos que pueden crear sujetos capaces de resistir y reconstituir el poder de diversas formas. Aquí, el trabajo de Judith Butler y otros teóricos queer ${ }^{5}$ 


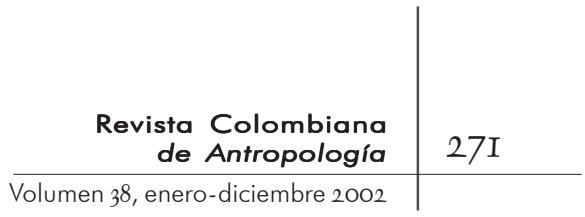

sobre la performatividad del discurso transmite algo de lo incompleto y abierto de los procesos de subjetivación.

\section{PERFormatividad}

ARA BUtLER, LA PERFORMATIVIDAD ES LA "PRÁCTICA REITERATIVA Y CITAcional por medio de la que el discurso produce los efectos a los que da nombre" (1993: 2). En Gender Trouble ${ }^{6}$, Butler explora la performatividad de forma específica con respecto al género. El género no es una característica esta-

6. Judith Butler. 2000. El género en disputa, feminismo y la subversión de la identidad. ble del sujeto que emana de una esPaidós. Barcelona (N. del t.). tructura binaria determinada por la biología o que está inscrita en lo cultural. En cambio, la identidad de género se practica por medio de la representación -performance-repetitiva de ciertos actos. El género debe ser re-presentado continuamente con el fin de asegurar su fijeza aparente. Esta noción de la representación iterativa como algo constitutivo de lo que se toma por una realidad estable ofrece ideas interesantes acerca de las políticas del conocimiento. Butler enfatiza sobre las diferencias inevitables entre los performances, los deslices entre las iteraciones, lo que sugiere que las identidades de género -o cualesquiera otras-, siempre son inacabadas y están abiertas a la subversión.

El concepto de performatividad abre un camino a través de la, a veces, desconcertante falta de piso del proyecto posestructuralista y apunta hacia las intervenciones comprometidas que retan los sistemas de saber/poder hegemónicos trazados claramente por Foucault. Lo que llama la atención de Butler son las aperturas por fuera del orden heteronormativo establecido, a través de las que se ven emerger los sujetos queer. Butler está comprometida con el proceso de desestabilizar las categorías binarias de género que sirven de soporte a la heterosexualidad obligatoria. Al enfatizar sobre las incertidumbres y discontinuidades inherentes a los performances de género, saca a la luz las posibilidades que existen para alterar e inventar dentro del proceso cultural de la creación del género. De esta forma, abre un espacio para la capacidad de actuar (agency) y lo impredecible en un modo de subjetivación que comúnmente se asume como un dato biológico o cultural. 


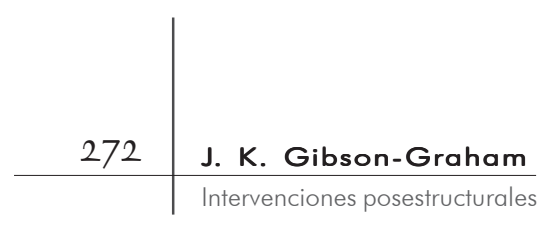

Para Butler y otros teóricos que hemos discutido aquí, las intervenciones estructurales no son una retirada hacia la teoría y una desconexión del mundo, la política, la ética o el cambio social. Al contrario, el posestructuralismo asigna un nuevo papel a la teoría, considerándola como una intervención política. El conocimiento posestructural da forma a la realidad en vez de reflejarla pasivamente. La producción de nuevos saberes es una actividad que cambia el mundo, reubicando otros saberes y validando nuevos sujetos, prácticas, políticas e instituciones.

\section{Momentos posestructuralistas EN LA GEOGRAFÍA ECONÓMICA}

N LA GEOGRAFía ECONÓMICA, LA RECONFIGURACIÓN POSESTRUCTURAL - de la relación entre conocimiento y acción, investigación y realidad, ha inspirado nuevas direcciones en la investigación. Ha aumentado también nuestra responsabilidad de preguntar, “¿En qué tipo de producción de conocimiento queremos participar? ¿Cuáles son los efectos del conocimiento que construimos? ¿Qué posibilidades genera nuestra investigación?”. En esta parte trataremos, brevemente, algunos de los trabajos en geografía económica animados por las estrategias de reconstrucción, genealogía y análisis discursivo, la teoría de la performatividad y una visión del investigador como agente/interventor.

\section{Deconstrucción}

T. K. Gibson-Graham (ig96) utilizan una aproximación deconstructiva en The End of Capitalism (As We Knew It), para enfatizar sobre las formas en que la construcción binaria capitalismo/no-capitalismo opera dentro del discurso económico para constituir al capitalismo como una forma de economía necesaria y naturalmente dominante. Las prácticas económicas no-capitalistas (dentro del hogar, el sector del mercado formal, la economía informal, los experimentos económicos alternativos o los intentos socialistas o cooperativistas) se entienden usualmente con respecto al capitalismo -como iguales a, lo opuesto de, complementarios, o contenidos dentro del capitalismo-; se 


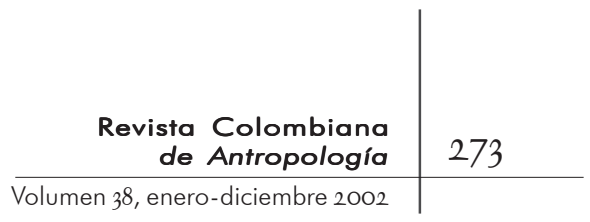

les ve como formas más débiles e incapaces de reproducirse. El no capitalismo se representa en los intersticios, en los enclaves experimentales o como algo disperso y fragmentado en el paisaje. El capitalismo, al contrario, se representa como algo sistémico, naturalmente expansivo y coterminal a la economía nacional o mundial. Como consecuencia de esto, muchos estudios sobre las actividades no-capitalistas se centran en su destrucción inminente, sus calidades protocapitalistas o su posición débil y determinada dentro de una economía local. Pocas veces se ve una representación de estas actividades como algo resistente, extendido, capaz de un crecimiento generativo o de impulsar el cambio económico. Ante la globalización, representada como la marcha a través del paisaje económico de un capitalismo aún más poderoso, las actividades no capitalistas pierden todo poder o son absorbidas.

Retomando las ideas de la teoría económica feminista y de los teóricos del sector informal, Gibson-Graham intentan debilitar el capitalocentrismo del discurso económico, tanto popular como académico, anotando que las actividades fuera del mercado y, por ende, no capitalistas, producen, por lo menos, la mitad de la producción total mundial. Sin embargo, en el discurso económico dominante, tanto de la izquierda como de la derecha, estas actividades, al igual que la producción no capitalista del mercado, subsisten bajo la sombra del capitalismo, de forma relativamente invisible y subordinadas a la posición dominante y a la importancia que se presume que tiene.

$\mathrm{Al}$ aproximarse a la estructura binaria capitalismo/no capitalismo, el principal movimiento deconstructivo de Gibson-Graham es darle una existencia independiente al término subordinado y negativo, representando positivamente lo no capitalista como una serie de formas económicas distintas y no, simplemente, como ausencia, insuficiencia o dependencia. Usando el lenguaje de la diferencia económica derivado de Marx, identifican en el paisaje una variedad de relaciones económicas además de la capitalista, incluyendo relaciones feudales, esclavistas, independientes y comunales en los sectores dentro y fuera del mercado. A medida que se van abriendo y escrutando las cajas negras de las economías formal, informal, alternativa y doméstica, la economía emerge como una interdependencia compleja de distintas relaciones económicas dentro de los diversos sectores constituidos del 
hogar, voluntario, independiente, empresa familiar, prisiones al igual que en el mercado industrial.

En un movimiento deconstructivo simultáneo, la unidad del otro lado de la estructura binaria puede disolverse y representarse como una multiplicidad contradictoria; el capitalismo puede privarse de su identidad sólida y coherente, volviéndolo distinto de lo que es y volviéndolo difícil de generalizar. Un acercamiento a este proyecto ha sido mediante la reconceptualización de la empresa. Tradicionalmente se ha asumido que las empresas comparten una estructura común, están motivadas por un imperativo común -la lógica del crecimiento, acumulación y ganancias- y enfrentan un terreno externo fundamentalmente similar, el mundo empresarial o el mercado. Sin embargo, la creciente literatura proveniente de la geografía económica, al igual que de la sociología económica, la antropología, la contaduría, la teoría organizativa y la economía política marxista enfatizan la heterogeneidad de las compañías. El trabajo de Erica Schoenberger (1997), por ejemplo, sobre la imbricación social de las empresas, traza los efectos de la cultura, la tradición y la afinidad sobre el comportamiento de las firmas, demostrando las formas en que los valores y las relaciones personales dentro de la administración debilitan gran parte de las metas corporativas de eficiencia y maximización de utilidades.

O’Neill y Gibson-Graham (1999) exploran el papel de los discursos administrativos en competencia, que le dan forma a esa entidad fluida denominada la empresa capitalista, que se representa sin problematizar. Al examinar una multinacional australiana minera y de acero producen lecturas alteradas que enfatizan sobre las acciones descentradas y desorganizadas que se toman en respuesta a las múltiples lógicas que circulan dentro y fuera de la corporación. Su análisis muestra a la empresa como un sitio impredecible y potencialmente abierto, y no como un conjunto de prácticas unidas por la lógica predecible de la maximización de utilidades y la acumulación capitalista. Al ser desatada de una lógica económica preordenada, la empresa se reconoce como una institución social común, que muchas veces no logra representar su voluntad ni cumplir sus objetivos o logra llegar, incluso, a una concepción coherente de lo que estos deben ser. En el contexto de tal representación, el subsumir capitalismo y poder y la noción relacionada de lo no capitalista como algo excluido del poder, se vuelve difícil de sostener. Al conceptualizar la economía 


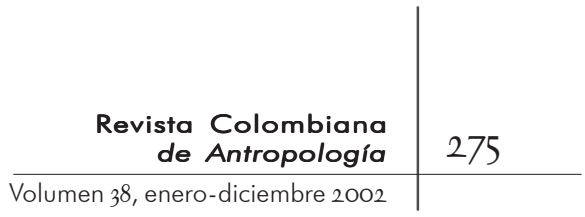

como diversa y heterogénea y no como si estuviera agrupada sobre un conjunto privilegiado de actividades u ordenada por una dinámica central, sino como algo siempre en proceso (discursivo) de construcción, Gibson-Graham (I996) han iniciado un proyecto para reconstruir el terreno político sobre el que las economías alternativas se imaginan o representan. Usando la deconstrucción para ampliar conceptos económicos e incluir actividades no remuneradas, fuera del mercado y no capitalistas, y para concebir la diferencia económica por fuera del marco binario, están produciendo una representación económica alternativa como una contribución a las formas innovadoras de políticas económicas y activismo.

\section{Genealogía y análisis del discurso}

I A INVESTIGACIÓN POSESTRUCTURALISTA SOBRE LA ECONOMÍA ENFATIZA L sobre la construcción discursiva y social de las economías locales, regionales, nacionales y globales, trabajando en contra de las representaciones dominantes de estas entidades como contenedores reales y determinantes de la vida social. Las literaturas sobre el posfordismo, la globalización y el desarrollo, por nombrar algunas, no se toman como descripciones sofisticadas de la realidad económica, sino como discursos que constituyen activamente la posibilidad económica, dándole forma y limitando las acciones de los agentes económicos y aquellos que dictan las políticas económicas.

Uno de los discursos predominantes que organiza el conocimiento en torno al cambio económico es el del desarrollo -la historia del crecimiento a lo largo de una trayectoria social universal en la que regiones o naciones caracterizadas por el atraso van progresando hacia la modernidad, la madurez y la realización de su potencial-. Este modelo de cambio orgánico ha estructurado el trabajo teórico en un amplio número de campos disciplinarios dispares, pero ahora se examina también por su eurocentrismo y sus efectos desvalorizadores y deshabilitadores sobre los menos desarrollados.

En la antropología, Arturo Escobar (1995) ha iniciado la tarea de hacer un análisis crítico y producir una genealogía del discurso del desarrollo. Su trabajo traza la producción histórica del 
tercer mundo -el conjunto de países cuyas poblaciones han sido representadas como iletradas, malnutridas, subempleadas y que requieren de ayuda y necesitan modelos occidentales de desarrollo-. El tercer mundo era un problema para el cual el desarrollo aportaba la solución -por medio del establecimiento de una serie de instituciones, prácticas y expertos a los que se les dio poder para ejercer su dominación en nombre del proyecto científicamente justificado del desarrollo-. La lectura minuciosa de Escobar revela cómo la práctica de identificar barreras para el crecimiento y prescribir caminos hacia el desarrollo ha sometido individuos, regiones y países enteros a los poderes y agencias del aparato desarrollista. Los sujetos producidos dentro de y por este discurso no tienen las capacidades necesarias para pensar por fuera de lo que se presume son el Orden y la Verdad de la narrativa del desarrollo económico y para rechazar la visión de una buena sociedad que proviene de occidente. La aproximación foucaltiana de Escobar al discurso del desarrollo ha abierto el camino para deshacer el tercer mundo, resaltando su construcción y la posibilidad de construcciones alternas. Su trabajo es muy importante para mostrar el camino para reubicar a los sujetos por fuera de un discurso que produce servilismo, victimismo e impotencia económica (Gibson-Graham y Ruccio, 1999).

Menos arraigado, aunque quizá más extendido, se encuentra el discurso de la globalización que circula hoy en día en las discusiones populares, académicas y políticas. En un texto reciente sobre la integración de la economía doméstica de Nueva Zelanda a las redes globales comerciales, financieras y de producción, Wendy Larner (I998: 600) se enfrenta a la narrativa de la globalización. Enfatiza en que la globalización no es, como muchos geógrafos económicos han argüido, una nueva realidad que fuerza a los estados nacionales y a sus ciudadanos a asumir nuevos roles, sino un discurso que plantea de manera poderosa una concepción distinta de la relación entre la economía internacional y nacional. En Nueva Zelanda, el imperativo de la globalización se ha constituido a partir de ambiciones políticas específicas, racionalidades y prácticas sociales. La actual representación de la economía neozelandesa como un "nodo de flujos y redes en la cuenca del Pacífico" (Larner, I998: 607) y no como una entidad autocontenida, ha promovido la entrada de nuevas formas de gobierno económico que privilegian al mercado sobre el estado para proveer socialmente, y sitúan al individuo dentro de un imaginario 


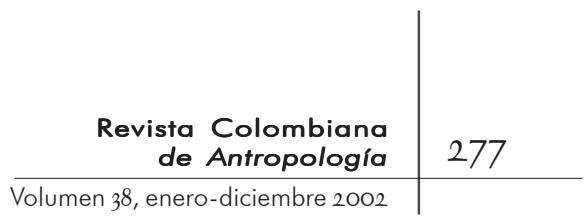

espacial global y no nacional. Larner asume como un aliciente que estos cambios sean el producto del actual, aunque no enteramente robusto, discurso dominante, para comenzar a identificar diferentes estrategias políticas e imaginarios espaciales alternos que puedan tener efectos más progresivos -o que al menos sean distintos-. Aunque no se omite el impacto real de la pérdida de empleos, la privatización, reorientación de capitales y el reemplazo de los viejos sistemas de gobierno por unos nuevos, Larner reta a los geógrafos económicos a que intervengan en la construcción del mundo que los rodea rehusándose a reificar la globalización como un fait accompli que existe fuera del discurso.

\section{Performatividad}

R ECONOCER LA PERFORMATIVIDAD DEL DISCURSO ES RECONOCER SU PODER, K su habilidad para producir "los efectos a los que da nombre" (Butler, I993: 2). Sin embargo, el proceso de repetición mediante el cual el discurso produce sus efectos se caracteriza por sus titubeos e interrupciones. Los estudios geográficos recientes sobre los sujetos económicos resaltan esta dimensión performativa del discurso. A diferencia del sujeto modernista racional y coherente, el sujeto económico posestructuralista está sujeto de forma incompleta. Su identidad siempre está en construcción y se compone parcialmente mediante las prácticas diarias y discontinuas que dejan espacios abiertos para la (re)invención y la perversión.

En el trabajo de Linda McDowell acerca del género en la City de Londres, por ejemplo, se representa a la masculinidad, la feminidad y la división del trabajo por género como algo que surge dentro de un medio geográfico y temporal particular y no como manifestaciones, dentro de un nuevo ambiente económico, de un sistema patriarcal de opresión. Mediante la observación del comportamiento, la forma de vestir y las actitudes en la bolsa de valores, y de entrevistas con las participantes de la banca empresarial, McDowell (1997) explora la manera en que se produce y se transforma el género en el mismo proceso de comprar y vender dinero, futuros y acciones. El género no se construye por fuera de la City y se lleva al trabajo sino que se constituye en y por medio 
de las prácticas económicas. Sus límites y posibilidades no son ordenados por un cuerpo sexuado, una estructura patriarcal o normas culturalmente transmitidas sobre el género sino que se construyen y reconstruyen en el momento del performance. "Al hacer claro que lo que parece ser una parte inalienable de un ser sexuado es realmente un performance espacial y temporalmente específico", McDowell (1997: 165) resalta la posibilidad de transformar y multiplicar estilos y prácticas corporales atrevidos que permiten nuevas formas de poder relacionadas con el género en los sitios de trabajo.

Jenny Cameron (1996/1997, I998) retoma la performatividad de género en un contexto comúnmente ignorado por los geógrafos económicos -los hogares de mujeres de la clase media australiana-. Cameron encuentra en estas economías domésticas la usual iniquidad de género en la división de las labores domésticas, pero escoge no interpretar la repartición desigual de las tareas domésticas como la persistencia de las estructuras patriarcales de la dominación masculina y explotación femenina. Su lectura meticulosa de los textos producidos en las entrevistas revela, en cambio, un proceso complejo mediante el cual ciertas tareas domésticas construyen la identidad heterosexual para los hombres y las mujeres. Acentuando la frontera precaria y móvil entre lo que es masculino y femenino en la sociedad australiana, Cameron muestra cómo los sujetos trabajan activamente para mantener la ficción de una identidad de género estable y natural, minada constantemente por sus vidas y contextos sociales. Más aún, los deslices y contradicciones inevitables entre los performances sugieren la posibilidad de géneros alternos y las diferentes sexualidades que señalan o permiten.

\section{Posestructuralismo}

\section{Y POLÍTICAS DE INVESTIGACIÓN}

ASTA ESTE PUNTO, CON SU ÉNFASIS SOBRE EL PODER CONSTRUCTIVO Y perturbador del discurso, la discusión sugiere que el posesTructuralismo alberga el potencial para ofrecer un nuevo modelo de investigación en geografía. Si al conocimiento no se le asigna la tarea de proveer un reflejo preciso de la realidad (Rorty, 1979), entonces la investigación no revela simplemente lo que 


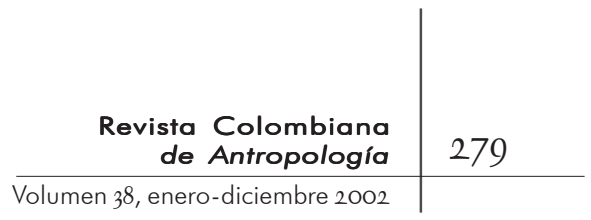

está allá afuera en el mundo. Reconocer la efectividad del saber da a la investigación un papel importante como actividad productora y transformadora de discursos, creando nuevas posiciones para los sujetos y posibilidades imaginativas que impulsen proyectos y deseos políticos (Gibson-Graham, 1994). En esta sección nos centramos en tres proyectos de investigación posestructurales que se preocupan por producir o desestabilizar formaciones discursivas, participando así en la constitución del poder, la subjetividad y la posibilidad social.

Geraldine Pratt (I999), en su estudio sobre trabajadoras domésticas filipinas y la segmentación del mercado laboral en Vancouver, esboza la forma en que algunos discursos sirven para devaluar y restarle poder a los inmigrantes filipinos. El proyecto crítico y genealógico de Pratt revela cómo las mujeres filipinas son asignadas a una gama de posiciones como sujetos y definidas en relación con lo que son inferiores a. Como enfermeras que viven en casa son identificadas como no-canadienses que aceptan empleos que ningún canadiense querría, sin tener acceso, hasta hace muy poco, a los derechos de que gozan los trabajadores canadienses. Como empleadas domésticas, muchas veces con una educación universitaria o profesional -por ejemplo enfermera registrada- en las Filipinas, se les considera menos calificadas que las niñeras europeas. Como filipinas dentro de su comunidad, se las ve como niñeras y no como inmigrantes comunes, siendo estigmatizadas, además, como roba maridos promiscuas. Pratt colaboró con organizadores del Centro de la Mujer Filipina, coordinando grupos de trabajo con las empleadas domésticas filipinas, en los que surgían estos discursos en los cuales su posición como sujeto era devaluada. Pratt enfatiza, sin embargo, sobre el hecho de que en el contexto de silencios e interrupciones surgieron discursos contradictorios y posiciones subjetivas alternas, lo que significa que el discurso nunca es capaz de ejercer el poder totalmente y de producir sujeción. Pratt (I999: 35) ve la posibilidad para la "acción, y para la reorientación creativa y la redefinición de las posiciones del sujeto" en la coexistencia de discursos contradictorios o inconmensurables. Cuando las trabajadoras domésticas empiezan a representarse ante sí mismas y ante sus empleadores como trabajadores y no como miembros de la familia, por ejemplo, pasan de una posición racial del sujeto dentro del discurso de inmigración y ciudadanía a una posición de clase del sujeto en un discurso laboral y de derechos laborales. 


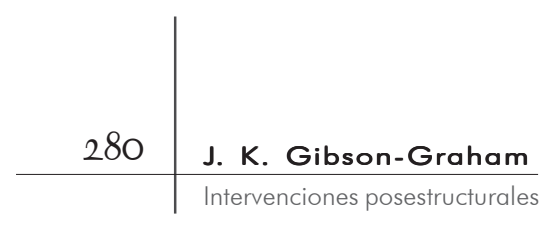

Pratt entiende su análisis crítico del discurso como una intervención que es "un elemento importante para interrumpir (...) prácticas institucionales opresivas". El análisis discursivo desnaturaliza las subjetividades y prácticas sociales, volviéndolas exóticas y extraordinarias como elementos de una formación en particular. El proceso de analizar un discurso resalta el carácter contingente de sus alineamientos y lo muestra como un intento de estabilización. De esta manera se sugiere, simultáneamente, su vulnerabilidad a la desestabilización y a la reconstrucción.

En el Proyecto de campo de Filadelfia, Lakshman Yapa (I999b) está intentando integrar la misión de enseñanza, investigación y servicio de la Pennsylvania State University con una intervención posestructural dentro de la pobreza urbana. El paso inicial y más crítico en este proyecto es cuestionar el discurso dominante de la pobreza, que según Yapa tiene tres características sobresalientes: I) asume que el conocimiento refleja significados que ya existen en los objetos; 2) está basado en una dualidad sujeto/ objeto en la que la pobreza es el objeto/problema y el científico social es el sujeto/no-problema; y 3) personifica una ontología esencialista en la que problemas como la pobreza tienen unas causas y soluciones fundamentales. En contraposición, Yapa propone que el significado se construye en el discurso, que las ciencias sociales son parte del problema de la pobreza y que las causas de la pobreza son "múltiples, difusas y están localizadas en sistemas sobredeterminados" (Yapa I999b: II).

El discurso dominante sobre la pobreza la trata como un problema que surge a raíz de la falta de ingresos. Los científicos sociales recogen información sobre los pobres para entender quiénes son y de dónde vienen, qué niveles de pobreza experimentan y por qué tienen ingresos insuficientes. Dependiendo del contexto político, quienes definen las políticas contra la pobreza pueden diseñar estrategias para mejorar el acceso a ingresos por parte de los sectores empobrecidos. Yapa ofrece una comprensión de la pobreza distinta y antiesencialista, considerándola como una construcción social multidimensional con una infinidad de orígenes y causas y, por ende, innumerables puntos de intervención. Reducir la pobreza a un problema de ingresos inadecuados sugiere no sólo que aumentar los ingresos aliviará los problemas de la pobreza, incluyendo la desnutrición, la falta de acceso a servicios de salud y de transporte, recursos educativos deficientes, vivienda por debajo de los estándares, sino que 


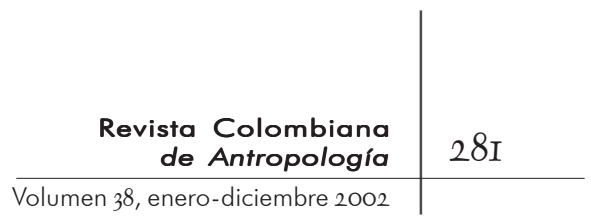

cierra (al invisibilizar) otras posibilidades de solucionar estas formas de privación.

En opinión de Yapa, la pobreza involucra la escasez de bienes básicos como comida, ropa, vivienda, salud y transporte, que se construyen de manera compleja por el conjunto total de condiciones que constituyen una sociedad. Ya que ninguna de estas condiciones es la causa fundamental de la pobreza, ninguna constituye una aproximación privilegiada para solucionarla: "La pobreza se crea en numerosos sitios distribuidos de forma amplia por la sociedad", así que "ningún gran proyecto de desarrollo económico, empleo, ingresos o acción afirmativa puede proveer una solución a la pobreza" (I999b: 8). El argumento de Yapa es que para enfrentar la pobreza podemos "empezar en donde estamos" y enfocarnos en aquellos agentes disponibles, su competencia sustantiva y en varias formas posibles de intervención. Así, un activista de la nutrición o la comida que no tiene conocimientos sobre una teoría económica del desarrollo no tiene que crear una zona empresarial para resolver el problema general del desarrollo sino que puede dirigirse específicamente a un problema sustantivo específico -por ejemplo, víveres y nutrición inadecuadas- por medio de educación nutricional, desarrollo de cooperativas para la compra de alimentos u organización de clases para la transferencia intergeneracional de conocimientos culinarios, etcétera.

Los estudiantes que participan en el Proyecto de campo de Filadelfia no hablan sobre la pobreza o la falta de ingresos con las personas que residen en áreas urbanas deprimidas, sino que hacen preguntas sustantivas acerca de los "problemas que tienen para satisfacer sus necesidades diarias de alimentación, vivienda, transporte, etcétera”. Esto está de acuerdo con una visión en la que no hay una lógica general para la pobreza, sino que existen condiciones específicas que construyen la escasez para cada caso. Los estudiantes tampoco se ofrecen a sí mismos como "agentes generales para el cambio" sino como individuos con cierto nivel de competencia sustantiva y la habilidad para crear conocimientos que pueden ser importantes para las necesidades de la comunidad. Al reconocer las formas en que la academia ha estado implicada en la pobreza, los estudiantes están intentando crear un saber y una práctica antipobreza que no se basa en una jerarquía sujeto/objeto sino en la especificidad de la escasez, la competencia sustantiva de las comunidades y la disponibilidad de agentes. 
Tanto en Estados Unidos de Norteamérica como en Australia, J. K. Gibson-Graham están haciendo investigación comunitaria regional, intentado generar un discurso de diversidad económica como una contribución a las políticas de innovación económica (Byrne et al., 1999). La fase australiana del proyecto se sitúa en una región donde la privatización de una central energética produjo altos niveles de desempleo y un sentimiento de victimismo y desesperanza regional. Al iniciar el proyecto, las investigadoras efectuaron mesas de trabajo con un amplio grupo de actores económicos -planificadores, empresarios, sindicalistas, trabajadores de los medios- y actores sociales y comunitarios -trabajadores del servicio social, el clero, artistas, educadores- para explorar las narrativas del cambio regional. En ambos grupos la historia que surgió de la reestructuración económica identificaba la economía regional con la minería y la producción de energía y destacaba la impotencia de los actores frente a las fuerzas nacionales y globales. Cuando se pidió a los grupos que pensaran acerca de las fortalezas y éxitos de sus comunidades, empezó a surgir una narrativa distinta, aunque titubeante, de diversidad económica y de innovación social y cultural (Gibson et al., I999). En conversaciones con algunos participantes se planeó un proyecto de investigación activa que pudiese empezar a desarrollar este discurso alternativo, aunque subordinado, de identidad regional y posibilidades económicas.

La investigación-acción participativa (IAP) es una práctica asociada tradicionalmente a los proyectos modernistas motivados políticamente. Diseñada para darle poder a comunidades marginales u oprimidas, esta metodología de investigación involucra a los miembros de las comunidades en el inicio, diseño, dirección y evaluación de la investigación (Fals Borda y Rahman, I99I). En su versión original, la IAP se ve como una manera para que las comunidades oprimidas reconozcan sus intereses comunes, basándose en una humanidad compartida o en sus experiencias estructuralmente determinadas de opresión. En la versión posestructuralista (Gibson-Graham, I994; Reinhaz, I992), la IAP supone generar conversaciones por medio de distintas identidades, construyendo comunidades parciales y temporales dentro de un "complejo y diverso 'nosotros"” (Fals Borda y Rahman, I99I: 8I). La interacción entre investigadores académicos y no-académicos durante el proceso de investigación genera nuevos 


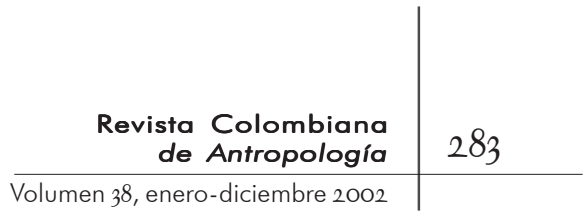

lenguajes y representaciones sociales que pueden constituir prácticas y visiones sociales alternas.

Durante las primeras etapas de la investigación australiana, tanto los académicos como los no-académicos reconocieron la importancia del lenguaje y la representación. Ante la ausencia de un lenguaje de diversidad económica, el discurso común del desarrollo había situado a la región como una entidad dependiente de la inversión por parte de firmas capitalistas que podían ser atraídas o no por varios argumentos. Esta visión, y la forma como los medios la presentaban, le habían dado el estatus de realidad desoladora, imposibilitando hablar con esperanza sobre la capacidad y el potencial regional. Al trabajar con investigadoras comunitarias el proyecto acción-participativa está diseñado para producir una balance alternativo de la economía regional, que reconoce una amplia variedad de relaciones y sujetos económicos, al igual que las dotes y capacidades particulares que poseen estos últimos (especialmente los pertenecientes a tres grupos marginados: trabajadores, jóvenes desempleados y madres solteras). Este balance alternativo servirá para desestabilizar la identidad primaria de esta área como una región de recursos. La compilación colectiva será un primer paso para crear oportunidades que reúnan a los nuevos actores regionales y a los distintos sujetos económicos para discutir y construir futuros regionales alternos.

En este proyecto de investigación posestructuralista la investigación es un proceso de creación de conversaciones mediante las que emergen nuevos lenguajes, identidades, comunidades y posibilidades sociales. Mesas de trabajo, entrevistas individuales, interacción entre académicos y no-académicos, conferencias comunitarias y otras conversaciones son los sitios y productos de la investigación. Un objetivo del proyecto es la producción de nuevos modelos de desarrollo regional que excedan la teoría y la práctica de la industrialización capitalista. Pero, y de igual importancia, es que la investigación busca validar un conjunto de sujetos económicos motivándolos a que intervengan en la conversación en proceso que es el desarrollo económico. De esta manera, el proyecto hará posibles nuevas identidades e iniciativas políticas. 


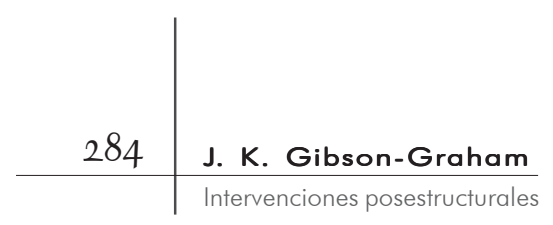

\section{Bibliografía}

Amariglio, J. I999. Poststructuralism. En J. Davis, D. Wade Hands y Uskali Maki (editores). Handbook of Economic Methodology. Edward Elgar. Cheltenham.

Brown, W. I99I. "Feminist hesitations, postmodern exposures". Differences. 3.

Butler, J. 1990. Gender Trouble: Feminism and the Subversion of Identity. Routledge. Nueva York.

-1993. Bodies that Matter: On the Discursive Limits of «Sex». Routledge. Londres.

Byrne, K., Forest, R., Gibson-Graham, J. K., Healy, S. y Horvath, G. 1999. Imagining and enacting noncapitalist futures. Rethinking Economy Project. Working Paper $\mathrm{n}^{\mathrm{O}}$ I. Dept. of Geosciences. University of Massachusetts. Amherst.

CAmERon, J. I996/97. "Throwing a dishcloth into the works: troubling theories of domestic labor". Rethinking Marxism. 9: 2.

. 1998. "The practice of politics: transforming subjectivities in the domestic domain and the public sphere". Australian Geographer. 29: 3.

DALY, G. I99I. "The discursive construction of economic space: logics of organization and disorganization". Economy and Society. 20: I.

DerRida, J. 1967. Of Grammatology. Traducción de G. Spivak. Johns Hopkins Press. Baltimore.

DoEL, M. I994. "Deconstruction on the move: from libidinal economy to liminal materialism". Environment and Planning. A. 26.

Escobar, A. 1995. Encountering Development: The Making and Unmaking of the Third World. Princeton University Press. Princeton.

Fals Borda, O. y Rahman, M. A. ig9i. Action and Knowledge: Breaking the Monopoly with Participatory Action Research. Apex. Nueva York.

Foucault, M. 1981. "The order of discourse. Inaugural lecture at the College de France, given 2 December 1970". En R. Young (editor). Untying the Text: A Poststructuralist Reader. Routledge \& Kegan Paul. Boston, Londres y Henley.

. I99I. "Politics and the study of discourse". En G. Burchell, C. Gordon y P. Miller (editores). The Foucault Effect: Studies in Governmentality with Two Lectures and an Interview with Michel Foucault. University of Chicago Press. Chicago. 


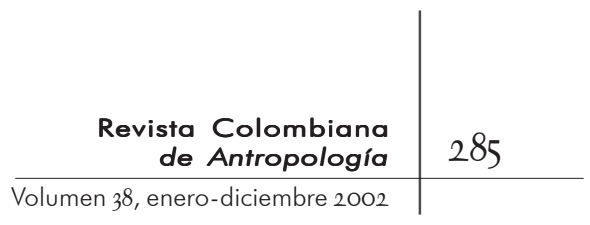

Gibson, K., Cameron, J. y Veno, A. I999. Negotiating Restructuring: A Study of Regional Communities Experiencing Rapid Social and Economic Change. Working Paper $\mathrm{n}^{\mathrm{O}} \mathrm{II}$. Australian Housing and Urban Research Institute.

Gibson, K. y Watson, S. I995. "Postmodern spaces, cities and politics: an introduction”. En S. Watson y K. Gibson (editores). Postmodern Cities and Spaces (I-I2). Blackwell. Oxford.

Gibson-Graham, J. K. I994. "Stuffed if I know!» Reflections on postmodern feminist social research”. Gender, Place and Culture. I: 2.

- 1996. The End of Capitalism (As We Knew It): A Feminist Critique of Political Economy. Blackwell. Oxford.

_. I997. "Re-placing class in economic geography: possibilities for a new class politics”. En R. Lee y J. Wills (editores). Geographies of Economies. Arnold. Nueva York.

Gibson-Graham, J. K. y Ruccio, D. i999. “'After' development: negotiating the place of class”. En J. K Gibson-Graham, S. Resnick y R. Wolff (editores). Re-presenting Class: Essays in Postmodern Political Economy (manuscript under review).

Gibson-Graham, J. K., Resnick, S. y WolfF, R. (editores). 200o. Class and its Others. University of Minnesota Press. Minneapolis.

Gross, E. I986. "Derrida and the limits of philosophy”. Thesis Eleven. I4.

Harvey, D. 1989. The Condition of Postmodernity. Blackwell. Oxford.

Hewitson, G. I999. "The body of economic theory: a feminist poststructuralist investigation”. En J. Amariglio, S. Cullenberg y D. Ruccio (editores). Postmodernism, Knowledge, and Economics. Routledge. Nueva York.

Jay, N. I99I. "Gender and dichotomy". En S. Gunew (editor). A Reader in Feminist Knowledge. Routledge. Londres.

LAMER, W. I998. "Hitching a ride on the tigers back: globalization and spatial imaginaries in New Zealand". Environment and Planning. D: Society and Space. I6: 5.

McDowell, L. I997. Capital Culture: Gender at Work in the City. Blackwell. Oxford.

O’Neill, P. y Gibson-Graham, J. K. I999. "Enterprise discourse and executive talk: stories that destabilize the company". Transactions: An International Journal of Geographical Research. 24: I.

PRATT, G. I999. "From registered nurse to registered nanny: discursive geographies of Filipina domestic workers in Vancouver, B. C.”. Economic Geography. 75: 3. 


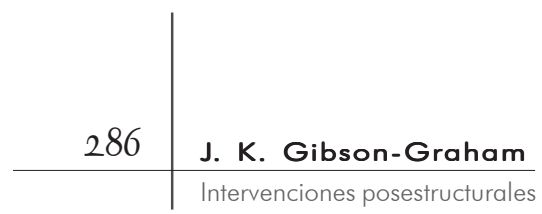

Reinharz, S. 1992. Feminist Methods in Social Research. Oxford University Press. Nueva York.

Rorty, R. 1979. Philosophy and the Mirror of Nature. Princeton University Press. Princeton, Nueva Jersey.

Ruccio, D. 1999. "Deconstruction". En J. Davis, D. Wade Hands y Uskali Maki (editores). Handbook of Economic Methodology. Edward Elgar. Cheltenham UK.

SAussure, F. DE. I966. (I9I5). Course in General Linguistics. En C. Bally y A. Sechehaye (editores). Traducción de W. Baskin. McGrawHill. Nueva York.

Schoenberger, E. 1997. The Cultural Crisis of the Firm. Blackwell. Oxford.

WARING, M. 1988. Counting for Nothing: What Men Value and What Women are Worth. Allen and Unwin. Sydney.

YAPA, L. I999a. "A primer on postmodernism with a view to understanding poverty". www.geog.psu.edu/-yapa/Discorse.htm I999b. "Integrating teaching, research, and service-a Philadelphia Field Project”. Unpublished paper, Dept. of Geography. The Pennsylvania State University, State College, PA. 